\title{
Parenting Self Efficacy Ayah dan Ibu pada Pasangan Suami Istri yang Menikah Dini
}

\author{
Inges Dwi Pangestu ${ }^{1}$ \\ Fakultas Psikologi, Universitas Muhammadiyah Malang \\ e-mail: 1ingesdwie@gmail.com
}

\begin{abstract}
Early married teenage couples have an impact on proper parenting in children. In order to be a good parent and can provide the right parenting for the child, then it takes high parenting self efficacy on parents. Parenting Self Efficacy is a belief in the competence that is held in organizing and executing a series of tasks on parenting. The purpose of this research is to describe parenting self efficacy father and mother on married couples in early marriage, the design of this research is quantitative descriptive, this study gives a detailed picture of an event based on the data that has been collected in the form of numbers, then analyzed and interpreted. The subject of this study is 30 couples who marry early with the age range of 17-20 years and have children aged 0-3 years. The sampling technique used is snowball sampling. The study used the Father Self Efficacy scale (FSES) scale for the Father And the maternal self efficacy Questioner (MSQ) scale for mothers. The results of this study were analyzed using SPSS. 21 for Windows using a descriptive test technique. The results of this study showed that the teenage father who has a high parenting selfefficacy that is $63 \%$ later on a teenage mother who has a high parenting self efficacy of $53 \%$.
\end{abstract}

\section{KEYWORDS Early marriage, parenting self efficacy}

CITATION Pangestu, I.D. (2020). Parenting self efficacy ayah dan ibu pada pasangan suami istri yang menikah dini. Cognicia, 8, (2). 262-276.

Menurut Mappiare (Ali \& Ansori, 2005) masa remaja berawal ketika individu berumur atau berusia dari 12 tahun sampai dengan 21 tahun bagi wanita dan untuk laki-laki yaitu ketika berumur 13 tahun sampai dengan 22 tahun. Menurut Havighurst (Hurlock E.B., 2004) tugas perkembangan pada masa remaja ini yaitu menjalin hubungan baru yang lebih matang dengan teman sebaya, mencapai kemandirian emosional dari orang tua maupun orang lain, mempersiapkan karir untuk masa depan, mencapai perilaku sosial yang bertanggung jawab serta mempersiapkan perkawinan dan keluarga.

Banyak faktor yang menjadi penyebab pernikahan usia dini, berdasarkan hasil penelitian yang dilakukan oleh Karismawati \& Lukitaningsih (2013) pernikahan dini yang terjadi didasarkan oleh dua faktor yaitu ada faktor intrinsik dan faktor ekstrinsik yaitu pengaruh dari teman sebaya yang mendorong remaja untuk melakukan pernikahan usia dini, selain itu akibat dari pergaulan bebas, ekonomi keluarga, budaya stempat dan orang tua. Menurut BKKBN (Wahyuni \& Rahmadewi, 2011) mengatakan dampak atau permasalahan yang diakibatkan oleh pernikahan dini salah satunya yaitu masalah organ reproduksi dan masalah sosial seperti tingginya angka kematian pada bayi. Kehamilan pada remaja juga beresiko terjadinya pendarahan, terganggunya pendidikan dan keadaaan psikologis seperti depresi pasca melahirkan dan perceraian, 10 dari 1000 remaja umur 10-14 tahun bersetatus cerai dan kurang gizi pada anak-anak mereka. Menurut data BKKBN tahun 2012 dampak 
negatif dari pernikahan dini ini juga yaitu sebesar 56\% remaja perempuan mengalami KDRT dalam frekuensi rendah. Di provinsi Nusa Tenggara Barat (NTB) dikatakan juga sebagai daerah darurat pernikahan dini. Usia pernikahan pertama perempuan di NTB masuk dalam katagori pernikahan dini yaitu sekitar $45,24 \%$ perempuan menikah di rentang usia 16-19 tahun (Susensas, 2013). Selain itu menurut Badan Pusat Statistika (BPS) NTB mencatat sepanjang tahun 2014, dari sekitar 2,3 juta jiwa perempuan di NTB lebih dari 50\% diantaranya menikah di bawah usia 20 tahun dan hampir 2\% diantaranya ialah berusia 10-14 tahun. Badan Kependudukan dan Keluarga Berencana Nasional (BKKBN) NTB mencatat Kabupaten Lombok Tengah dan Lombok Timur menjadi daerah darurat pernikahan dini.

Secara psikologis perempuan yang menikah usia dini belum memiliki kesiapan dalam menjalankan peran sebagai seorang ibu karena ibu remaja belum memiliki kematangan jiwa dan kemantapan untuk berpikir dan berbuat. Serta remaja yang menikah di usia dini juga belum memiliki pandangan dan pengetahuan yang cukup tentang bagaimana seharusnya peran sebagai seorang ibu dan seorang istri atau peran seorang laki-laki sebagai bapak dan kepala rumah tangga. Maka dari itu batas usia sangat penting untuk melangsungkan suatu pernikahan, hal ini karena pernikahan menghendaki kematangan psikologis. Latiana (2010) mengatakan bahwa usia orang tua merupakan salah satu faktor yang membentuk pengasuhan pada anak. Usia pasangan yang relatif muda umumnya sulit menyesuaikan diri dengan pasangannya karena belum memiliki kematangan untuk mengendalikan emosi.

Selain cenderung menimbulkan konflik karena emosi yang belum stabil pada pasangan yang menikah dini, rumah tangga pada pasangan dini ini juga cenderung menghadapi problematika serta permasalahan rumah tangga yang juga berdampak pada pengasuhan anak yang dilahirkan. Seperti yang dikatakan oleh Ancok (dalam Yulianti, 2010) yaitu, anak-anak yang lahir dari ibu berusia remaja memiliki tingkat kecerdasan yang lebih rendah dibandingkan dengan anak-anak yang dilahirkan oleh ibu dari orang tua yang usianya lebih dewasa. Rendahnya angka kecerdasan tersebut terjadi dikarenakan ibu remaja belum dapat memberikan stimulasi mental pada anak-anaknya.

Penelitian yang dilakukan oleh Dewi, Hardiani (2014) mengatakan bahwa bayi yang yang dilahirkan oleh remaja beresiko sembilan kali lebih besar meninggal karena diakibatkan oleh kecelakaan serta penganiyayaan daripada bayi yang lahir dari ibu yang berusia lebih tua. Dari penelitian sebelumnya diatas dapat diambil kesimpulan bahwa tingkat parenting self efficacy (PSE) ibu dari remaja dapat dikatakan rendah karena ibu remaja cenderung lebih emosional sehingga mempengaruhi kemampuan pengasuhan mereka, self efficacy yang rendah juga akan memunculkan stress dan depresi pada ibu sehingga berdampak pada pola perilaku pengasuhan orang tua terhadap anak mereka. Jadi parenting self efficacy ini sendiri sangat penting untuk dimiliki oleh orang tua dalam mengasuh anak mereka, parenting self efficacy (PSE) adalah suatu keyakinan yang dimiliki oleh orang tua terkait dengan kemampuan mereka dalam mengatur dan menjalankan serangkaian tugas-tugas tentang pengasuhan anak (Montigny \& Lacharite, 2005).

Ayah mempunyai 3 peran penting atau utama dalam pengasuhan yaitu dalam aspek afeksi, pengasuhan, dan dukungan finansial. Aspek afeksi yaitu peran ayah dalam memberikan perhatian, membahagiakan, memberikan rasa aman, serta memberikan perhatian saat sakit. Aspek kedua yaitu aspek pengasuhan, ayah disini berperan dalam meluangkan waktu, memberi nasehat, mengingatkan, mengajar, serta menjaga anak. Aspek ketiga yakni aspek dukungan finansial, ayah berperan memberikan makan, serta memberikan uang jajan, dan juga memenuhi kebutuhan hidup keluarga (Harmaini \& Yulianti, 2015). Menurut Malelak \& Alfiatin (2015) ayah berusia remaja cenderung 


\section{Cognicia}

mengalami kesuliatan dalam bidang prekonomian, keterbatasan sumber daya, dan cenderung belum mandiri sehingga masih bergantung pada orangtua, sehingga menimbulkan rasa malu dalam diri ayah remaja karena merasa belum berhasil sepenuhnya menjalankan perannya sebagai orangtua. Menurut Benson (dalam Malelak \& Alfiatin, 2015) ayah remaja lebih rentan mengalami depresi dan masalah kesehatan mental karena memiliki sumber daya ekonomi yang sangat sedikit, serta memiliki sedikit kesempatan dalam mendapatkan pekerjaan yang lebih baik.

Peran dan pengasuhan yang dilakukan oleh ayah akan mempengaruhi perkembangan serta kesejahtraan anak pada masa transisi menuju remaja (Cabrera, Tamis, Bradley, Hofferth, \& Lamb, 2000). Kelekatan hubungan emosional seorang ayah dengan anak akan mempengaruhi perkembangan kognitif serta kompetensi sosial pada anak (Hernandez \& Brown, 2002 dalam Wahyuningrum, 2014).

Profe dan Wild (2015) didalam penelitiannya mengatakan bahwa keterlibatan kedua orang tua yaitu ayah dan ibu di dalam pengasuhan sangat berhubungan dengan bagaimana anak menyelesaikan masalah. Kerjasama antara ayah dan ibu di dalam pengasuhan pada remaja yang mengkonsumsi rokok ternyata dapat mengurangi jumlah rokok yang digunakan. Hal ini membuktikan bahwa ketika ayah dan ibu bekerjasama terlibat dalam pengasuhan anak, maka akan berdampak positif pada kehidupan dan perkembangan anak sehingga dapat mengurangi perilaku negatif atau perilaku yang tidak diinginkan dikemudian hari.

Parenting self efficacy merupakan pengembangan dari konsep self efficacy yang dikemukakan oleh Bandura. Bandura (dalam Gao, Sun \& Cha, 2014) menjelaskan bahwa selfefficacy adalah keyakinan seseorang terhadap kompetensi yang dimilikinya bahwa ia mampu untuk menyelesaikan tugas tertentu dengan baik. Self efficacy sendiri menentukan bagaimana seseorang merasa, berpikir, serta memotivasi diri serta berperilaku. Mengacu pada konsep tersebut, parenting self efficacy merupakan kepercayaan seseorang terhadap dirinya sendiri atau terhadap kompetensi yang dimiliki untuk menjalankan peran sebagai orang tua dan persepsi terhadap kemampuannya untuk membawa pengaruh positif pada perilaku serta perkembangan anak (Coleman \& Karraker, 2000). Keyakinan terhadap kompetensi diri sendiri tersebut, menurut (Gilmore dan Cuskelly, 2008) merupakan faktor pendorong bagi orang tua untuk mempraktekkan pola parenting yang efektif pada anak. Orang tua yang mempunyai parenting self efficacy yang baik akan dapat membantu anak-anak mereka melawati fase perkembangan anak mereka tanpa masalah yang serius. Sebaliknya orang tua yang memiliki parenting self efficacy yang kurang baik maka akan cenderung rentan terhadap stress dan dapat lebih mudah mengalami depresi terhadap tuntutan keluarga yang semakin banyak (Bandura, 1994). Jika orang tua mempunyai parenting selfefficacy yang rendah dalam diri mereka maka akan berimbas pada ketidakmampuan dalam menggunakan pengetahuannya untuk bertindak terhadap tugas sebagai orang tua yang pada akhirnya akan mampu menimbulkan tekanan emosi yang tinggi serta ketidakteguhan dalam proses parenting (Grusec et al, 1994 dalam Coleman, 1998). Perasaan kurang yakin terhadap kemampuan diri sendiri dalam menjalankan peran tersebut merupakan aspek penting yang akan berpengaruh pada perilaku parenting yang ditampilkan (Hastings \& Brown 2002).

Penelitian ini penting untuk dilaksanakan mengingat pentingnya peran parenting self efficacy (PSE) dalam diri orangtua. Karena orangtua merupakan orang pertama yang akan memberikan pengasuhan pada anak maka diharapkan orang tua mempunyai parenting self efficacy yang tinggi. Orangtua yang mempunyai parenting selfefficacy yang rendah akan mudah 
mengalami depresi serta stress yang mana nantinya hal tersebut akan mempengaruhi pengasuhan yang akan diberikan kepada anak, seperti contohnya orangtua akan cenderung kasar serta cenderung memberikan hukuman-hukuman kepada anak, oleh karena itu orangtua penting untuk memiliki parenting self efficacy yang tinggi agar dapat memberikan pengasuhan yang baik pada anak yang mana pengasuhan ini akan berdampak kepada perkembangan yang optimal pada anak. Dibutuhkan sikap positif dari orangtua untuk membimbing tumbuh kembang anak agar anak dapat berkembang sesuai dengan tahap perkembangannnya. Pengasuhan yang baik dapat berdampak positif dalam perkembangan kognitif, sosial, emosi, kehidupan dan lingkungan anak. Adapun tujuan dari penelitian ini adalah untuk mendeskripsikan parenting selfefficacy (PSE) ayah dan ibu pada pasangan suami istri yang menikah pada usia dini. Manfaat teoritis dari penelitian ini adalah diharapkan mampu menambah refrensi dalam bidang psikologi khususnya psikologi keluarga. Sedangkan manfaat praktisnya adalah untuk mengetahui gambaran parenting selfefficacy pada pasangan suami istri yang menikah di usia dini, serta dapat dijadikan sebagai acuan dalam pemberian informasi pentingnya parenting self efficacy yang tinggi oleh kedua orang tua untuk mendukung perkembangan anak. Selanjutnya untuk lembaga-lembaga yang bertanggung jawab agar dapat mengembangkan dan mengoptimalkan kegiatan-kegiatan atau seminar yang bersifat pemberian pengetahuan yang berkaitan dengan pengasuhan anak yang tepat, agar orang tua khususnya pada remaja yang menikah pada usia dini siap untuk menjadi orangtua

\section{METODE PENELITIAN}

Jenis penelitian ini menggunakan pendekatan kuantitatif dengan desain penelitian deskriptif yaitu penelitian ini akan menggambarkan situasi atau kejadian tidak bermaksud mencari penjelasan, menguji hipotesis atau implikasi dan data yang dikumpulkan berupa angka untuk menemukan keterangan yang ingin diketahui.

Populasi dalam penelitian ini adalah remaja yang menikah dini yaitu pada usia 12 sampai dengan 20 tahun di daerah Kecamatan Praya Tengah Kabupaten Lombok Tengah. Sampel dalam penelitian ini sebanyak 30 pasangan suami istri. Teknik sampling yang digunakan adalah snowball sampling. Teknik ini dipilih karena peneliti hanya mengenal satu atau dua orang saja yang cocok dengan penilaiannya yang bisa dijadikan sebagai sampel dalam penelitian.

Variabel dalam penelitian ini yaitu parenting self efficacy (PSE). Parenting self efficacy (PSE) adalah suatu keyakinan yang dimiliki oleh orangtua baik ayah maupun ibu terkait dengan kompetensi mereka dalam pengasuhan, bahwa mereka mampu dengan baik serta efektif untuk mengerjakan semua tugas-tugas yang berkaitan dengan mengasuh anak serta dapat menghasilkan perkembangan yang baik untuk anak mereka. untuk mengukur PSE ayah yaitu menggunakan skala Father Self- Efficacy Scale (FSES) yang telah disusun oleh Sevigny (2013). Skala ini terdiri atas 22 item dan tersusun atas 9 dimensi yaitu, dimensi teaching, parenting in context, financial responsibility, safety and protection, discipline and control, nurturing, accessibility, instrumental care and routines, dan play. PSE ibu menggunakan skala Maternal Self Efficacy Questioner (MSQ) yang disusun oleh Teti \& Gelfand (1991). Penyusunan skala mengacu pada aspek-aspek yang diungkap oleh Bandura (1997) yaitu yaitu domain spesifik maternal self efficacy dan global self efficacy.

Tabel 1. Indeks Validitas dan Reliabilitas Alat Ukur Penlelitian 


\begin{tabular}{lll}
\hline Alat Ukur & Jumlah Item Valid & Indeks Realiabilitas \\
\hline Father Self Efficacy Scale & 16 & 0,918 \\
\hline Maternal Self Efficacy & 11 & 0,87 \\
\hline
\end{tabular}

Berdasarkan uji validitas dan reliabilitas try out, ditemukan bahwa jumlah item valid pada alat ukur father self efficacy scale berjumlah 16 item dengan reliabilitas sebesar 0.918. sedangkan jumlah item valid pada alat ukur maternal self efficacy berjumlah 11 item dengan realiabilitas 0.87 .

\section{HASIL PENELITIAN}

Pada penelitian ini subjek yang digunakan yaitu sebanyak 60 subjek.Deskripsi subjek penelitian ialah sebagai berikut:

Tabel 1. Deskripsi Subjek Penelitian

\begin{tabular}{ccc}
\hline Kategori & Frekuensi & Persentase \\
\hline Perempuan & & \\
$17-18$ & 11 & $37 \%$ \\
$19-20$ & 19 & $63 \%$ \\
Laki-laki & & \\
$17-18$ & 2 & $7 \%$ \\
$19-20$ & 28 & $93 \%$
\end{tabular}

Berdasarkan gambaran hasil Tabel 1. dapat dilihat bahwa dari 60 subjek penelitian didominasi oleh remaja berusia 20 tahun yaitu sebanyak 41 orang. Perempuan berjumlah 14 orang dan laki-laki berjumlah 27 orang.

Tabel 2. Parenting Self Efficacy berdasarkan Jenis kelamin

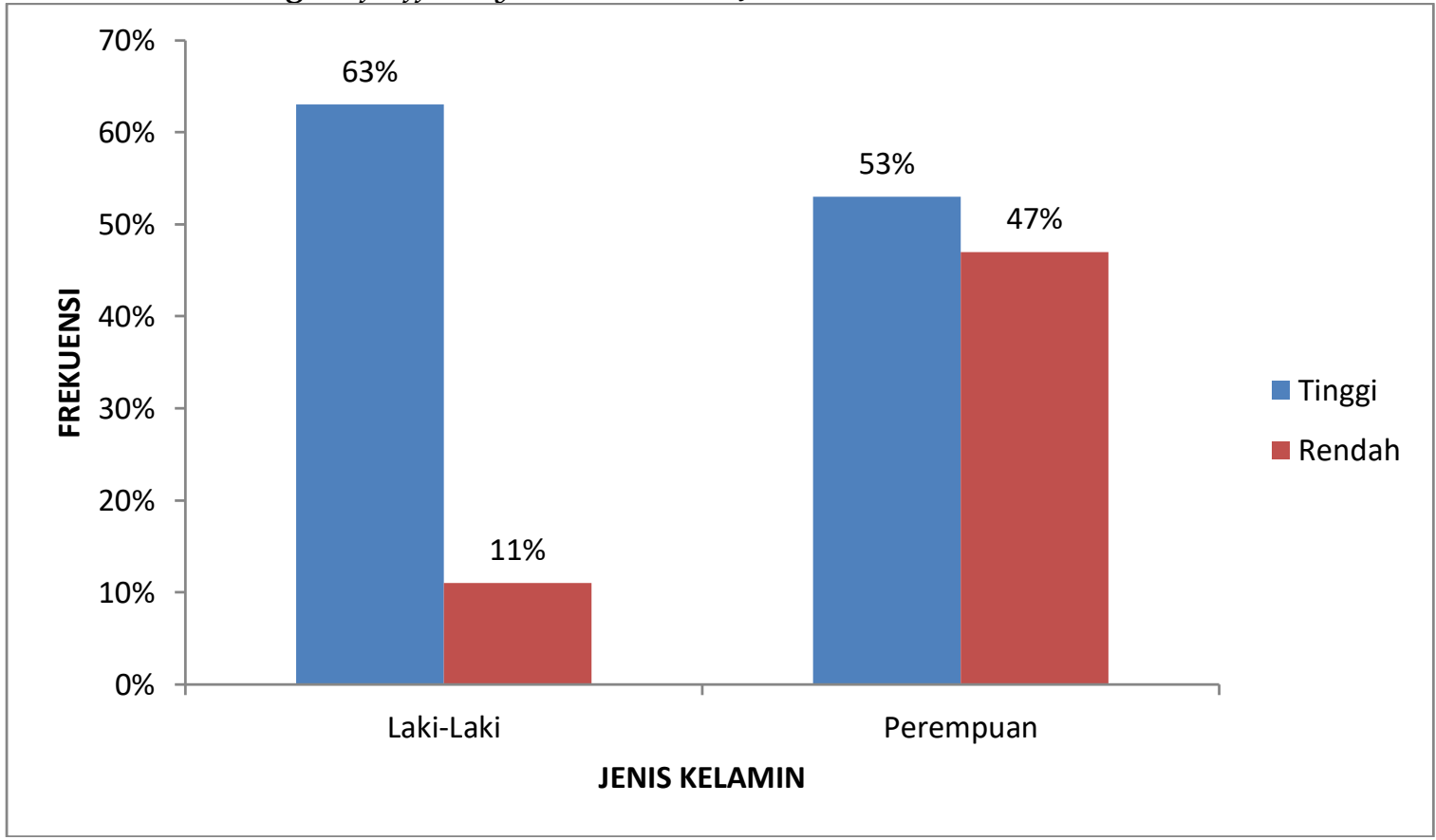


Berdasarkan gambaran hasil Tabel 2, dapat dilihat bahwa parenting self efficacy pada laki-laki yang tinggi yaitu sebanyak (63\%), sedangkan yang perempuan sebanyak (53\%).

Tabel 3. Parenting Self Efficacy berdasarkan Tempat Tinggal

\begin{tabular}{ccccc}
\hline Tempat Tinggal & \multicolumn{2}{c}{ PSE Ayah } & \multicolumn{2}{c}{ PSE Ibu } \\
& $\mathbf{T}$ & $\mathbf{R}$ & $\mathbf{T}$ & $\mathbf{R}$ \\
\hline Rumah orang tua & $12(71 \%)$ & $5(29 \%)$ & $11(65 \%)$ & $6(35 \%)$ \\
Rumah pribadi & $6(55 \%)$ & $5(45 \%)$ & $4(36 \%)$ & $7(64 \%)$ \\
Kontrak & $1(50 \%)$ & $1(50 \%)$ & $1(50 \%)$ & $1(50 \%)$ \\
\hline
\end{tabular}

Berdasarkan gambaran hasil Tabel 3, dapat dilihat bahwa parenting self efficacy berdasarkan tempat tinggal pada pasangan remaja yang menikah dini di Kecamatan Praya Tengah pada Ayah dan Ibu yang tertinggi terdapat pada pasangan yang tinggal di rumah orang tua.

Tabel 4. Parenting Self Efficacy berdasarkan Usia Ayah dan Ibu

\begin{tabular}{ccccc}
\hline Usia & \multicolumn{2}{c}{ PSE Ayah } & \multicolumn{2}{c}{ PSE Ibu } \\
& $\mathbf{T}$ & $\mathbf{R}$ & $\mathbf{T}$ & $\mathbf{R}$ \\
\hline $17-18$ & $1(50 \%)$ & $1(50 \%)$ & $5(45 \%)$ & $6(54 \%)$ \\
$19-20$ & $18(64 \%)$ & $10(36 \%)$ & $11(58 \%)$ & $4(42 \%)$ \\
\hline
\end{tabular}

Berdasarkan gambaran hasil Tabel 4, dapat dilihat bahwa parenting self efficacy berdasarkan usia pada pasangan remaja yang menikah dini di Kecamatan Praya Tengah pada ayah dan ibu yang tertinggi terdapat pada usia 19-20 tahun.

Tabel 5. Parenting Self Efficacy Ayah berdasarkan Aspek PSE Ayah

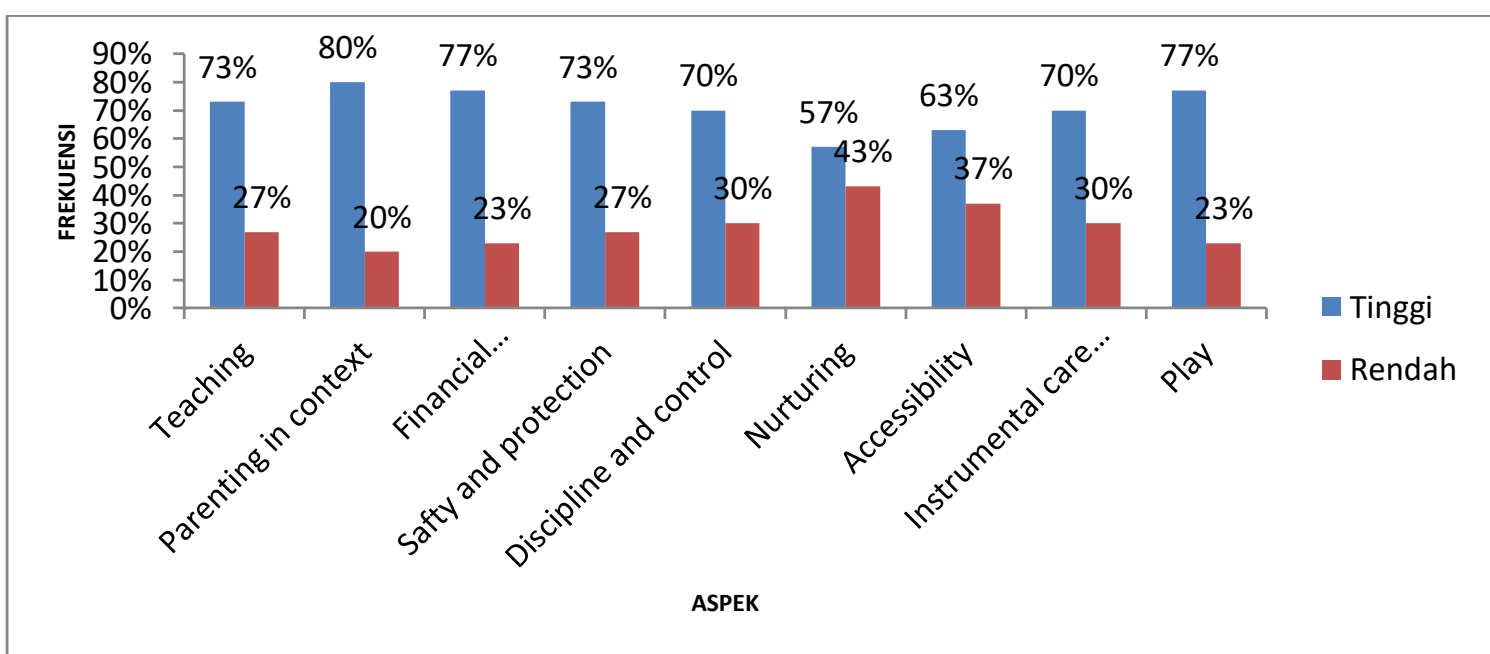

Berdasarkan gambaran hasil dari Tabel 5, menunjukkan bahwa aspek yang paling tinggi pada 30 sampel ayah remaja di Kecamatan Praya Tengah Kabupaten Lombok Tengah terdapat pada aspek Parenting in context dan yang terendah terdapat pada aspek Nurturing.

Tabel 6. Parenting Self Efficacy Ibu berdasarkan Aspek PSE Ibu 


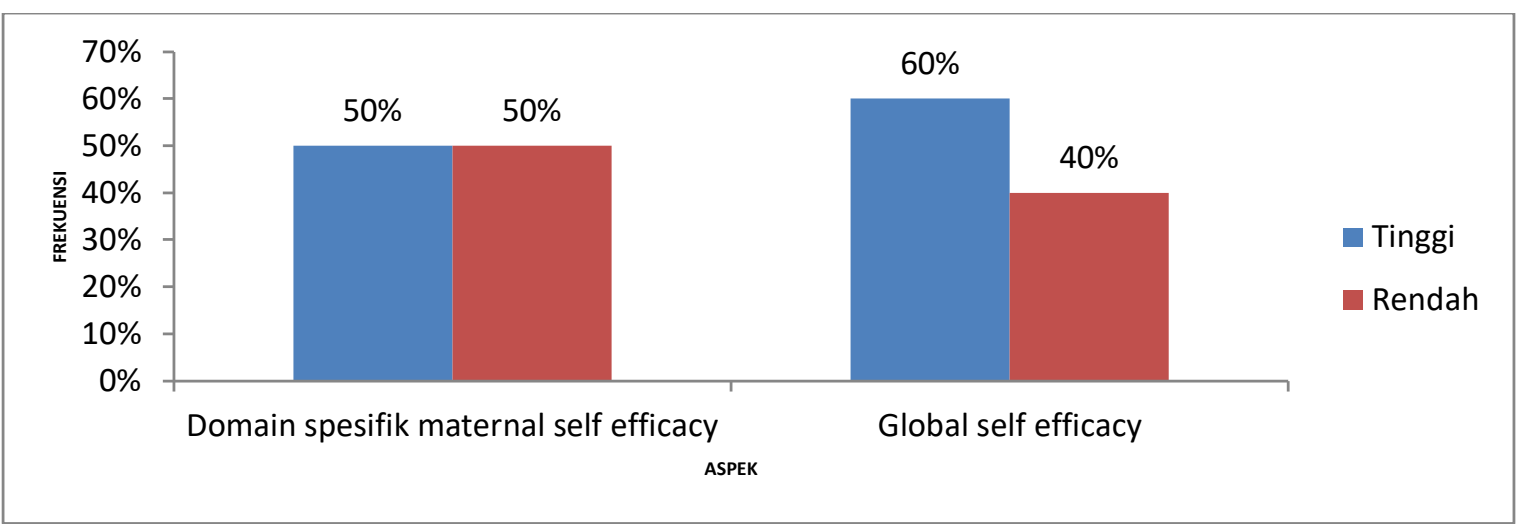

Berdasarkan gambaran hasil dari Tabel 6, menunjukkan bahwa aspek yang paling tinggi pada 30 sampel ibu remaja di Kecamatan Praya Tengah Kabupaten Lombok Tengah terdapat pada aspek global self efficacy dan aspek yang terendah terdapat pada aspek domain spesifik maternal self efficacy.

Tabel 7. Parenting Self Efficacy Ayah dan Ibu berdasarkan Lama Pernikahan

\begin{tabular}{ccccc}
\hline Usia pernikahan & \multicolumn{2}{c}{ PSE Ayah } & \multicolumn{2}{c}{ PSE Ibu } \\
& $\mathbf{T}$ & $\mathbf{R}$ & $\mathbf{T}$ & $\mathbf{R}$ \\
\hline 1-2 Tahun & $17(74 \%)$ & $7(29 \%)$ & $13(54 \%)$ & $11(46 \%)$ \\
2 > Tahun & $2(28 \%)$ & $4(66 \%)$ & $3(50 \%)$ & $3(50 \%)$ \\
\hline
\end{tabular}

Berdasarkan gambaran hasil dari Tabel 7, menunjukkan bahwa parenting self efficacy ayah dan ibu ditinjau berdasarkan usia pernikahan yang tertinggi terdapat pada usia pernikahan 1-2 tahun.

Tabel 8. Parenting Self Efficacy berdasarkan pekerjaan Ayah

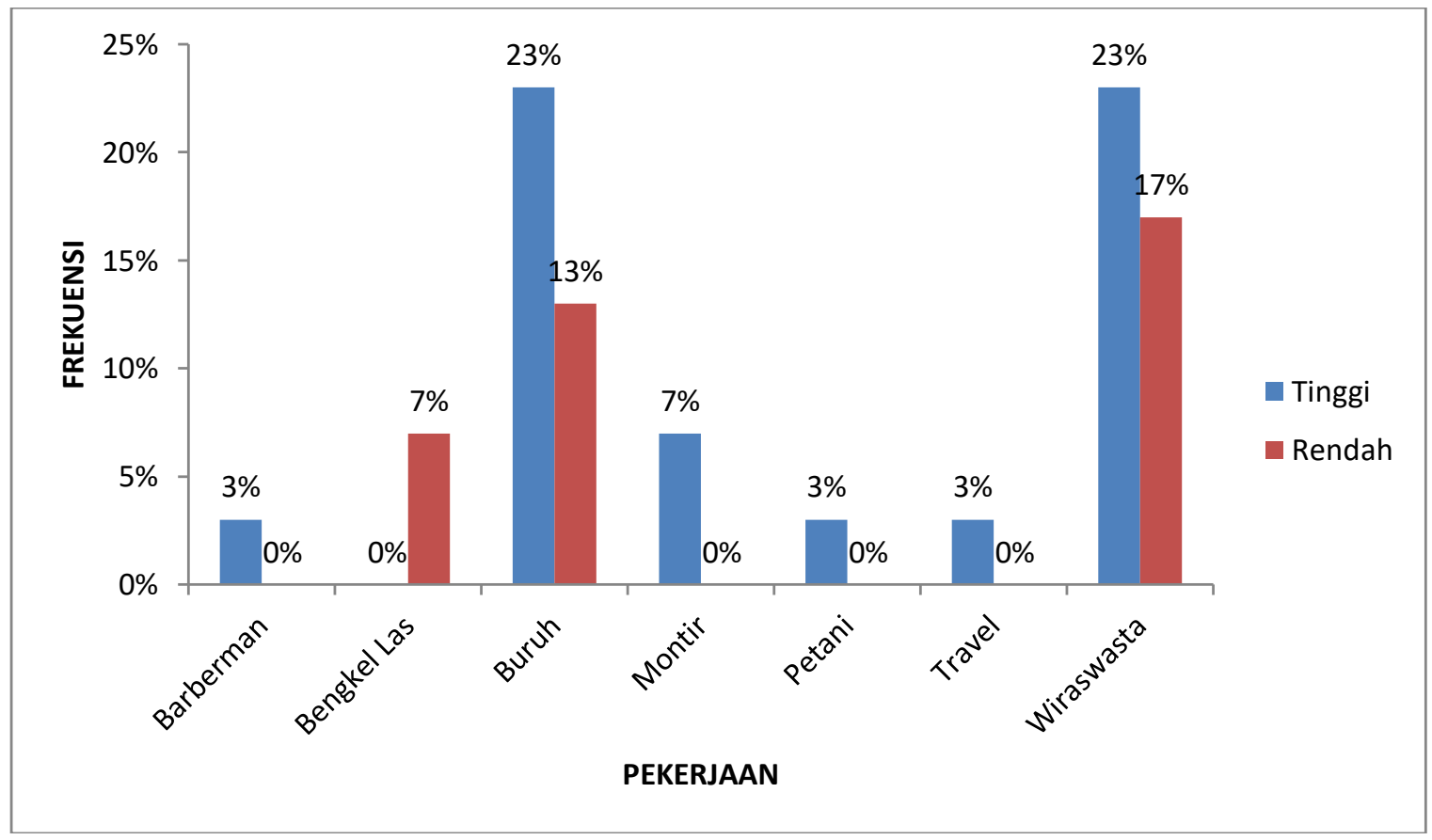


Berdasarkan gambaran hasil dari Tabel 8, menunjukkan bahwa parenting self efficacy ayah yang tinggi terletak pada ayah yang mempunyai pekerjaan sebagai wiraswasta dan buruh.

Tabel 9. Parenting Self Efficacy berdasarkan perkiraan penghasilan perbulan

\begin{tabular}{ccccc}
\hline Penghasilan & \multicolumn{2}{c}{ PSE Ayah } & \multicolumn{2}{c}{ PSE Ibu } \\
& $\mathbf{T}$ & $\mathbf{R}$ & $\mathbf{T}$ & $\mathbf{R}$ \\
\hline$<1 \mathrm{jt}$ & $13(62 \%)$ & $8(38 \%)$ & $12(52 \%)$ & $11(48 \%)$ \\
$1-2 \mathrm{jt}$ & $5(63 \%)$ & $3(37 \%)$ & $4(57 \%)$ & $3(43 \%)$ \\
$3-5 \mathrm{jt}$ & $1(100 \%)$ & $0(0 \%)$ & $0(0 \%)$ & $0(0 \%)$ \\
\hline
\end{tabular}

Berdasarkan gambaran hasil dari Tabel 9, menunjukkan bahwa parenting self efficacy ayah yang tertinggi adalah ayah yang mempunyai penghasilan 3-5 jt sedangkan pada ibu parenting self efficacy ibu yang tertinggi terletak pada ibu yang mempunyai penghasilan 1-2 jt.

Tabel 10. Parenting Self Efficacy berdasarkan usia anak

\begin{tabular}{ccccc}
\hline Usia Anak & \multicolumn{2}{c}{ PSE Ayah } & \multicolumn{2}{c}{ PSE Ibu } \\
& $\mathbf{T}$ & $\mathbf{R}$ & $\mathbf{T}$ & $\mathbf{R}$ \\
\hline$\leq 18$ bulan & $17(65 \%)$ & $9(35 \%)$ & $15(58 \%)$ & $11(42 \%)$ \\
$\geq 18$ bulan & $2(50 \%)$ & $2(50 \%)$ & $1(25 \%)$ & $3(75 \%)$ \\
\hline
\end{tabular}

Berdasarkan gambaran hasil dari Tabel 10, menunjukkan bahwa parenting self efficacy ayah dan ibu yang tinggi terletak pada usia anak dibawah 18 bulan, sedangkan parenting selfefficacy ayah dan ibu yang terendah terdapat pada anak yang berusia diatas 18 bulan.

\section{DISKUSI}

Parenting self efficacy ditinjau berdasarkan jenis kelamin, dapat dilihat dari hasil penelitian diatas bahwa ayah remaja memiliki parenting self efficacy lebih banyak yang tinggi. Apabila dilihat lagi salah satu faktor yang dapat mempengaruhi parenting self efficacy ayah tinggi adalah adanya dukungan sosial dari orang terdekat yaitu orangtua, disini kebanyakan pasangan yang menikah dini tinggal bersama orangtua mereka sehingga mendapatkan dukungan yang lebih dari orangtua yang mana dukungan sosial yang didapat dari orangtua tersebut berdampak kepada tingkat parenting self efficacy yang dimiliki oleh ayah. Seperti yang dikatakan oleh Coleman \& Karraker dalam Hardiyanti (2017) terdapat beberapa hal yang dapat mempengaruhi terbentuknya PSE diantaranya yaitu lingkungan dan dukungan sosial yang didapatkan oleh ayah, yaitu dukungan yang berasal dari keluarga, pasangan dan teman, serta keberfungsian hubungannya dengan lingkungan sosial seperti kepuasan pernikahan dan keberfungsian keluarga. Selain dukungan sosial faktor lain yang dapat mempengaruhi PSE ayah yaitu vicarious experience. Menurut Coleman \& Karraker (1997) mengatakan bahwa vicarious experience yaitu pengalaman mengamati orang lain sehingga pengamatan tersebut membentuk suatu keyakinan dalam diri terhadap kompetensi yang dimiliki. Vicarious experience ini juga dapat didefinisikan sebagai bagaimana pengamatan ayah terhadap parenting yang diterapkan oleh orang tuanya terdahulu, khususnya bagaimana parenting ayah terhadap dirinya. Seperti yang dikatakan oleh Wood \& Lambin (2013) pengalaman ayah dengan orang tuanya dulu dapat mempengaruhi bagaimana perannya dalam parenting saat ini. 
Selanjutnya hasil penelitian diatas didapati bahwa ibu remaja memiliki parenting self efficacy lebih banyak yang rendah. Ibu remaja yang memiliki PSE yang rendah bisa saja disebabkan karena ibu remaja belum siap secara psikologis untuk menjadi seorang ibu. Seperti halnya penelitian yang dilakukan oleh Abdi (2018) yang mengatakan bahwa ibu remaja lebih menonjolkan sifat keremajaan yaitu antara lain belum stabil, belum mempunyai pemikiran tentang masa depan yang mantap, dan masih berada dalam masa transisi yang penuh dengan konflik. Hal ini juga di dukung pada penelitian yang dilakukan oleh Fajriyah N, Laila Q, \& Marisa F (2019) yang mengatakan bahwa ibu usia remaja kurang mampu dalam mengerti perasaan anak ketika anak merasa tersakiti serta kurang bisa memberikan kenyamanan ketika anak membutuhkan mereka disaat anak merasa dalam keadaan takut ataupun frustasi. Perasaan kurang mampu yang dialami ibu remaja bisa saja dikarenakan ibu remaja harus menangani tugas-tugas perkembangan yang berpotensi bertentangan dengan tugas pengasuhan. Selain itu kondisi emosional ibu remaja yang belum stabil karena akibat perkembangan neurofisiologis yang belum matang juga dapat mempengaruhi ibu dalam mengasuh anak, contohnya yaitu ibu remaja menunjukkan perilaku pengasuhan yang kurang responsif dan sensitif.

Parenting self efficacy ditinjau berdasarkan usia, pada remaja di kecamatan Praya Tengah kabupaten Lombok Tengah diketahui bahwa ayah remaja yang berusia 19-20 tahun memiliki parenting self efficacy lebih banyak yang tinggi dibandingkan ayah remaja yang berusia 17-18 tahun. Begitupun dengan ibu remaja juga memiliki parenting self efficacy lebih banyak yang tinggi pada usia 19-20 tahun. Hal ini seperti yang dikatakan oleh Putro (2017) pada masa remaja akhir ini remaja sudah bisa berfikir secara realitis lebih baik, memiliki sikap pandang yang sudah baik, lebih matang dalam menghadapi masalah, dan ketenangan emosional bertambah serta lebih mampu menguasai perasaan. Santrok (2013) juga mengatakan bahwa semakin bertambah usia remaja maka akan semakin stabil emosi, cara berfikir, kosentrasi dan minat serta kemampuan dalam menyelesaikan masalah sudah mulai meningkat.

Parenting self efficacy ayah dilihat berdasarkan aspek PSE Ayah menunjukkan bahwa ayah remaja dalam penelitian ini mempunyai parenting self efficacy yang tinggi dalam aspek parenting in context dimana disini parenting in context yaitu proses parenting yang terjadi dalam konteks yang spesifik yaitu hubungan antara ayah dan ibu serta bentuk negosiasi orangtua. Hal ini menunjukkan bahwa ayah dan ibu dalam penelitian ini memiliki hubungan yang baik serta mampu menegosiasi mengenai pengasuhan secara spesifik, yaitu melakukan pembagian tugas pengasuhan kepada pasangan. Tingginya aspek Parenting in context yang dimiliki oleh ayah bisa saja dipengaruhi oleh budaya yang dimilikinya. Hal ini seperti yang dikatakan oleh Harmaini (2015) fungsi serta peran orang tua dalam keluarga tidak bisa dilepaskan begitu saja dari pengaruh budaya orang tua yang bersangkutan. Apa yang diajarkan oleh budaya tentang bagaimana berkeluarga otomatis akan diturunkan pada anak secara turun temurun. Parenting self efficacy ayah remaja yang rendah terdapat pada aspek nurturing dimana disini ayah remaja kurang bisa dalam menunjukkan kasih sayang kepada anak seperti kurangnya perhatian, kurang bisa dalam memahami mood anak serta belum bisa memberikan respon yang tepat pada anak.

Parenting self efficacy ibu dilihat berdasarkan aspek PSE Ibu menunjukkan bahwa ibu remaja dalam penelitian ini mempunyai parenting selfefficacy yang rendah dalam aspek domain spesifik maternal self efficacy yang berarti ibu remaja disini kurang memiliki keyakinan bahwa ia mampu dalam melakukan tugas-tugas pengasuhan, seperti memberi makan atau 
memandikan bayi, menenangkan bayi ketika menangis, serta kurang bisa mengerti apa yang diinginkan atau dibutuhkan bayi. Hal ini seperti yang dikatakan oleh Abdi (2018) yang mengatakan bahwa secara psikologis ibu remaja belum siap untuk menjadi seorang ibu dalam hal keterampilan dalam mengurus anak. Ibu remaja yang menikah dini juga dianggap kurang dalam hal kesiapan kognitif seperti kurangnya pengetahuan ibu akan tugas sebagai orang tua serta kurang memiliki pengetahuan mengenai tahap perkembangan bayi (Crugnola, 2014). Jika dibandingkan dengan ibu usia dewasa, ibu remaja lebih cenderung untuk menonjolkan sifat keremajaannya daripada sifat keibuan serta ibu usia dewasa juga lebih bisa untuk mengendalikan emosi maupun tindakannya dibandingkan dengan ibu usia remaja (Purnawati, 2015). Selanjutnya PSE ibu remaja yang tinggi terdapat pada aspek global self efficacy yang mana aspek tersebut menggambarkan perasaan yang lebih global pada self efficacy ibu, disini ibu remaja merasa bahwa ia sudah melakukan yang terbaik dalam menjadi seorang ibu walaupun hal yang mereka lakukan belum maksimal untuk anak mereka.

Parenting self efficacy ayah dan ibu ditinjau berdasarkan usia pernikahan. Dapat dilihat dari hasil tabel 6 diatas bahwa ayah dan ibu remaja mempunyai parenting self efficacy yang tinggi pada usia pernikahan 1-2 tahun. Awal pernikahan merupakan masa yang bisa disebut masa yang sangat berbahagia bagi pasangan suami istri, karena baru menjalankan rumah tangga dan belum diterpa berbagai masalah dalam rumah tangga. Menurut Coleman \& Karraker (dalam Medieni, 2013) Ada beberapa faktor yang mempengaruhi pembentukan parenting self efficacy, yang pertama yaitu pengalaman masa kecil orangtua, budaya dan komunitas (lingkungan sekitar), pengalaman orangtua dengan anak-anak, tingkat kesiapan kognitif maupun perilaku menjadi orangtua, dan dukungan sosial dan pernikahan.

Parenting selfefficacy ayah ditinjau berdasarkan pekerjaan ayah, dapat dilihat dari tabel diatas bahwa PSE ayah yang tertinggi terdapat pada ayah yang bekerja sebagai wiraswasta dan buruh. Menurut penelitian yang dilakukan oleh Benu, Thoomaszen, Kiling- Bunga, \& Kiling dalam Hanifah (2019) mengatakan bahwa ayah yang bekerja sebagai wiraswasta memiliki paternal responsibility yang tinggi. Jenis pekerjaan ayah akan mempengaruhi keterlibatan pengasuhan ayah kepada anak, yang dimana pekerjaan ayah ini membutuhkan waktu yang tidak terlalu padat serta fleksibel sehingga ayah mempunyai cukup waktu untuk terlibat di dalam pengasuhan anak sehingga akan berpengaruh terhadap tingkat PSE yang dimilikinya. Benu juga mengatakan bahwa jenis pekerjaan yang memiliki tingkat tekanan stres kerja yang rendah, tantangan yang tinggi, serta mandiri dalam bekerja cenderung akan lebih ramah, menolong serta peduli terhadap anak. Parenting self efficacy ayah dilihat dari ratarata penghasilan yang didapatkan perbulan di dapatkan hasil bahwa ayah yang mempunyai penghasilan 3-5 jt memiliki parenting self efficacy yang lebih tinggi dibandingkan dengan ayah yang memiliki penghasilan dibawahnya. Ini menunjukkan bahwa semakin besar tingkat pendapat yang dimiliki oleh ayah maka semakin tinggi pula tingkat PSE yang dimiliki oleh ayah. Hal ini dikarenakan ketika ayah memiliki pendapatan yang besar maka ayah akan mampu memenuhi tanggung jawab secara finansial terhadap keluarganya serta mampu untuk mempersiapkan ketersedian finansial untuk kebutuhan jangka panjang. Hal ini juga akan mempengaruhi persepsi ayah terhadap kemampuannya dalam mengasuh anak khususnya dalam hal tanggung jawab secara finansial.

Parenting Self Efficacy ditinjau berdasarkan usia anak, dapat diketahui bahwa PSE ayah dan ibu yang tinggi terletak pada usia anak dibawah 18 bulan. Sedangkan PSE ibu dan ayah yang rendah terletak pada usia anak diatas 18 bulan. Hal ini seperti yang dikatakan oleh Belsky (dalam Sanderson \& Thompson, 2002) yang mengatakan bahwa faktor-faktor yang mempengaruhi pengasuhan salah satunya yaitu karakteristik anak seperti usia, urutan 


\section{Cognicia}

kelahiran, jenis kelamin, serta temperamen anak. Anak yang berusia dibawah 18 bulan juga umumnya memiliki kebutuhan yang lebih sedikit dibandingkan anak yang berusia diatas 18 bulan sehingga hal ini akan berpengaruh terhadap kemapuan finansial yang diberikan, khususnya oleh ayah. Hal ini seperti yang dikatakan oleh Garcia dan Alampay (2012) mengatakan bahwa kondisi finansial untuk membesarkan anak dapat menjadi situasi yang membuat stress dan depresi pada ayah remaja sehingga akan mempengaruhi PSE yang dimilikinya.

Keterbatasan dalam penelitian ini adalah tidak mengukur peran ayah dan ibu di dalam pengasuhan. Disamping itu, skala yang digunakan pada ibu diadaptasi dari penelitian yang ditunjukkan pada ibu yang baru saja melahirkan sebagai subjek penelitiannya, sedangkan pada penelitian ini subjek yang digunakan bukan hanya pada ibu yang baru saja melahirkan melainkan pada ibu yang sudah mempunyai anak usia toddler. Keterbatasan lain dalam penelitian ini juga yaitu penilaian terhadap PSE subjek, dilakukan oleh diri sendiri sehingga bersifat sangat subjektif dan belum tentu akurat terhadap PSE yang dimiliki oleh subjek.

\section{SIMPULAN DAN IMPLIKASI}

Berdasarkan penelitian yang telah dilakukan pada pasangan suami istri yang menikah dini di Kecamatan Praya Tengah Kabupaten Lombok Tengah, didapatkan hasil bahwa ayah yang mempunyai parenting self efficacy yang tinggi jumlahnya lebih banyak dibanding ibu yang mempunyai parenting self efficacy tinggi, dan ayah yang mempunyai parenting self efficacy rendah jumlahnya lebih sedikit dibanding ibu yang mempunyai parenting self efficacy rendah.

Implikasi dari penelitian ini adalah karena parenting self efficacy mempunyai peranan yang sangat penting dalam hal pengasuhan anak maka dibutuhkan adanya PSE yang tinggi dari kedua belah pihak agar dapat menghasilkan pengasuhan yang berkualitas. Ayah dan ibu diharapkan saling bekerjasama dan saling memberi dukungan agar keduanya dapat mempunyai parenting self efficacy yang tinggi, karena dukungan sosial dari pasangan ataupun orang terdekat sangat berpengaruh terhadap parenting self efficacy baik ayah maupun ibu. Ayah dan ibu juga disarankan melakukan aktivitas yang dapat meningkatkan PSE seperti mencari informasi terkait dengan bagaimana pentingnya peran kedua orangtua terhadap tumbuh kembang dan psikologis anak, atau dapat mengikuti edukasi ataupun seminar yang berkaitan dengan bagaimana pengasuhan anak yang baik.

Implikasi untuk penelitian selanjutnya diharapkan ketika proses pengerjaan skala ayah dan ibu duduknya tidak berdekatan, dengan tujuan agar ayah dan ibu tidak berdiskusi saat peroses pengerjaan skala yang nantinya hal itu dapat menimbulkan bias pada hasil skala. Selanjutnya untuk skala yang digunakan mungkin lebih disesuaikan lagi dengan subjek penelitian yang akan diteliti. Selain skala yang digunakan untuk mengukur PSE ayah dan ibu, dibutuhkan juga tes yang sifatnya berupa penalaran tentang kasus-kasus pengasuhan anak untuk mengukur tingkat PSE yang dimiliki ayah dan ibu, karena penggunaan skala saja tidak dapat mengkur secara pasti tingkat PSE yang dimiliki oleh ayah dan ibu, karena skala tersebut bersifat sangat subjektif yang dimana hal tersebut bersifat belum tentu akurat.

\section{REFERENSI}

Abdi, F.H. (2018). Pernikahan dini dalam perspektif psikologi komunikasi. JURNAL Darusalam; Jurnal Pendidikan, Komunikasi dan Pemikiran Hukum Islam, Vol. IX, No 2, pp. 385-397. 
Ahmed, S., Khan, S., Alia, M., \& Noushad, S. (2013). Psychological impact evaluation of early marriages. International Journal Of Endorsing Health Science Research, Vol.1, No.2, pp.84-86

Andayani, B., \& Koentjoro. (2004). Peran ayah menuju coparenting. Sepanjang: CV. Citra Media.

Ali, M., \& Asrori, M. (2005). Psikologi remaja perkembangan peserta didik. Jakarta: PT Bumi Aksara.

Alwisol, R. (2004). Psikologi kepribadian. Malang: UMMPress.

Bandura, A. (1997). Self efficacy: toward aunifying theory of behavioral change. Psycchological Review. Vol 84, No 2, 191-215.

...........(1994).SelfefficacyRerieved fromhttp://www.des.emory.edu/mfp/BanEncy.html

BKKBN. (2013). kajian pernikahan dini pada beberapa provinsi di indonesia : dampak overpopulation, akar masalah, dan peran kelembagaan di daerah. Link (diakses pada tanggal X Juni 2019 Pukul 20.00)

Borntein, M. H. (1998). Refocusing on parenting. Diakses dari. Pada tanggal 6 April 2019, from https://parenthood.library.wisc.edu/Bornstein/Bornstein.html.

Cabrera, N., Tamis-Lemonda, C., Bradley, R., Hofferth, S., \& Lamb, M. (2000). Fatherhood in the twenty first century. Child Development, Vol 71, 127-136.

Coleman, P.K., \& Karraker, K.H. (2005). Parenting self efficacy , competence in parenting, and possible links to young children's social and academic outcomes. Dalam O.N. Saracho \& B.Spedek (Eds). Contemporary perspective on families, communities, and schools for young children.

(2000). Parentinng self efficacy among mother of school agechildren:

conceptualization, measurment, and coreelates. Family Reltions, 49 (01), 13-24.

.(1998). Maternal self-efficacy beliefs as predictors of parenting competence and toddlers emotional, social, and cognitive development. Dissertations doktoral.West Virginia University.

(1997). Self-efficacy and parenting quality: findinngs and future applications. Developmental Review. West Virginia University.

Crugnola, R.C., Lerardi, E., Gazzotti, S., \& Albizzati, A. (2014). Motherhood in adolescent mothers: maternal attachment, mother-infant styles of interaction and emotion regulation at three months. Infant Behaviour and Development, 44-56.

Donovan, W. L., \& Leavitt, L. A. (1985). Simulating conditions of learned help lessness: the effects of interventions and attributions. Child Development, 56, 594-603

Desjardin, J. L. (2001). Assesing parental perceptions of self efficacy and involvement in family of young children with hearing loss. The Volta Review, Vol 103(4), 391-409.

Dewi, R.O.W., Hardiani, R. S., \& Dewi, E. I. (2014). Hubungan riwayat usia pernikahan dengan sikap ibu dalam perawatan bayi lahir di wilayah kerja puskesmas Silo Kabupaten Jember. Artikel Ilmiah Hasil Penelitian Mahasiswa. Jember: Program Studi Ilmu Keperawatan Universitas Jember.

Dumka, L. E., Gonzales, N. A., Wheeler, L. A., \& Millsap, R. E. (2010). Parenting self-efficacy and parenting practices over time in mexican american families. Journal of Family Psychology, 24 (5), 522-531.

Eaton, M. M. (2007). Self-efficacy in first-time mothers: a comparison of younger and older mothers. Doctoral Dissertation, University of Kansas. 
Fajriyah, N., Laila, Q., Marisa, F.M. (2019). Komparasi parenting self efficacy pada ibu usia remaja dan dewasa di Kecamatan Banjarharjo Brebes. Jurnal Psikologi Sains Dan Profesi, Vol. 3, No 1 pp. 12-20

Fogarty, K., \& Evans, G. D. (2009). The hidden benefits of being an involved father. Department of family, youth and community sciences, Florida cooperative extension service, Institute of food and agricultural sciences, University of Florida.

Gao, L. L., Sun, K., \& Chan, S. W. C. (2014). Social support and parenting self- efficacy among Chinese women in the perinatal period. Midwifery, 30(5),532-538.

Garcia, A. S., \& Alampay, L. P. (2012). Parental efficacy, experience of stressful life events, and child externalizing behavior as predictors of Filipino mothers'and fathers' parental hostility and aggression. Philippine Journal of Psychology, $45(1), 1$.

Gilmore, L.A., \& Cuskelly, M. (2008). Factor structure of parenting sense of competence scale using a normative sample. Child care, health, E development, 38 (1), 48-55. Gyesaw,

N.Y.K \& Ankomah, A. (2013). Experiences of pregnancy and motherhood among teenagers mothers in a suburb of Accra, Ghana: a qualitative study. Journal of Women Health. 773-780.

Hanifah., Karmiyati D., \& Hidayati D.S. (2019). Efikasi diri pengasuhan ayah. Skripsi, Program Sarjana. Universitas, Muhammadiyah Malang.

Harmaini, H., Shofiah, V., \& Yulianti, A. (2015). Peran ayah dalam mendidik anak. Jurnal Psikologi, 10(2), 80-85.

Harty, M. (2009). The validation of a task-specific measure of parenting self-efficacy for use with mothers of young children. Doctoral dissertation, University of Pretoria.

Hardyanti S., Karmiyati D., \& Hidayati D.S. (2017). Parenting self efficacy ayah pada nuclear dan extended family. Jurnal Ilmiah Psikologi Terapan, Vol 5, No 2.

Hastings, R. \& Brown, T. (2002). Behaviour problems of children with autism, parental self efficacy and mental health. American journal of mental retardation, 107 (3), 222-232.

Holloway, S.D., Suzuki, S., Yamamoto, Y., \& Behrens, K.Y.(2005). Parenting self efficacy

among japanese mothers. Journal of Comparative Family Studies, $\quad 36,1$.

Hurlock, E.B. (2004). Psikologi perkembangan. Jakarta: PT. Gelora Aksara Pratama.

(1978). Perkembangan anak Jilid 2 Edisi 6. Jakarta: Erlangga.

Jeckson, AP \& Scheines, R. (2005). Single Mothers Self efficacy, Parenting in The Home Environment, and Childrens Development in two wave Study. Sosial Work Research; Mar 2005; 29, 1; ProQuest pg.7

Jones, T.L., \& Prinz, R.J. (2005). Potential roles of parental self efficacy in parent and child adjustment: A review. Clinical psychological review, 25(3). 341-363.

Karismawati, L. (2013). Studi tentang faktor-faktor yang mendorong remaja melakukan pernikahan dini di Kecamatan Kemlagi Kabupaten Mojokerjo. Journal mahasiswa

bimbingan konseling. Vol 1No 1: 50-60.

Latiana, L. (2010). Pendidikan anak dalam keluarga. Universitas Negeri Semarang.

Malelak, V. Y., \& Afiatin, T. (2015). Makna peran ayah pada ayah remaja. JurnalPsikologi "MANDIRI", 1(2).

Madieni, A.Y., Erniza, M.M., Efriyani, D. (2013). Perbedaan parenting self efficacy pada ibu dengan status sosial ekonomi menengah ke atas dan bawah yang memiliki anak usia kanak-kanak madya.

Montigny, D. F., \& Lacharité, C. (2005). Perceived parental efficacy: Concept analysis. Journal of Advanced Nursing, 49, 387-396. 
Ormrod, J. E. (2008). Psikologi pendidikan. (6 $6^{\text {th }}$ ed). Jakarta: Penerbit Erlangga

Palkovitz, R. (2002). Involved fathering and child development: Advancing our understanding of good fathering, In C. S. Tamis-LeMonda \& N. Cabrera (Eds.), Handbook of father involment: Multidisicplinary perspectives (pp. 119-140). Mahwah, New Jersy: Lawrence Erlbaum Associates.

Pratama, A. B. (2014). Perspektif remaja tentang pernikahan dini. Bengkulu. Fakultas ilmu sosial dan ilmu politik. Skripsi,Program Sarjana. Universitas, Bengkulu

Profe,W., \& Wild, L. (2015). Mother, father, and grandparents involment : associations with adolesecent mental health and substance Use. Journal of Family Issues, 1-22.

Putro, K. (2017). Memahami ciri dan tugas perkembangan masa remaja. Jurnal aplikasi ilmu-ilmu agama.Vol 17 No 1.

Purnawati, L. (2015). Dampak perkawinan muda terhadap pola asuh keluarga (Studi di desa Talang Kecamatan Sendangan Kabupaten Tulungagung). Jurnal Publiciana. Vol. 8, No 1.

[RISKESDAS] Riset Kesehatan Dasar. (2010). Badan penelitian dan pengembangan kesehatan, Departemen Kesehatan, Republik Indonesia.

Saderson, S., \& Thompson, V.L.S. (2002). Factors associated with perceived paternal involvement in childrearing. Sex Roles : A Journal of Research.Vol. 46

Santrok, John W. (2007). Perkembangan anak jakarta : Penerbit Erlangga.

Secer, Z., \& Ogelman, G. (2012). Analysing mothers' self efficacy perception towards parenting in relation to peer relationships of 5-6 year-old pre-school children. Education Sciences: Theory and Practice, 12(3), 2001-2008.

Sevigny, P.R.(2013).Understanding parental self-efficacy in fathers. Doctoral dissertation,

Faculty of Graduate Studies and Research, University of Regina.

Siahaan, H.N. (1991). Peran ibu bapak mendidik anak. Bandung : Angkasa.

Teti, D.M., \& Gelfand, D.M. (1991). Behavioral competence among mother of infants in the first year: The Mediational Role Of Maternal Self Efficacy. Child Development, 62, 918-929.

Tomezewski, D.K. (2009). Predictors of anticipated parenting efficacy in younger adults. Thesis, West Virginia University of Morgantown.

Tsou, L.M. (2010). The realeation of childhood memories and husband support to prenting selfefficacy in japanese mothers. Dissertation doctoral, University of California, Berkeley.

Volker, J., \& Gibson, C. (2014). Paternal involvement: A review of the factors influencing father involvement and outcomes. TCNJ Journal of Student Scholarship, 15, 1-8.

Wahyuningrum, E.(2014). Peran ayah (fathering) pada pengasuhan anak usia dini (Sebuah Kajian Teoritis). Indonesia: Universitas Kristen Satya Wacana.

Wahyuni, D., \& Rahmadewi. (2011). Kajian profil penduduk remaja (10-24 tahun): ada apa dengan remaja?. Jakarta: Seri I No 6/Pusdu-BKKBN/Desember 2011/Pusat Penelitian dan Pengembangan Kependudukan-BKKBN.

Whiteside-Mansell, L., Pope, S. K., \& Bradley, R. (1996). Patterns of parenting behavior in young mothers. Family Relations, 45(3), 273-281.

Wood, L., \& Lambin, E. (2013). How fathers and father figures can shape child health and wellbeing. The University of Western, Australia.

Yulianti, R. (2010). Dampak yang ditimbulkan akibat perkawinan usia dini. Journal Of Social Sciences, Economics And Humanities, Vol 3, No 1. 


\section{Cognicia}

http://ejournal.umm.ac.id/index.php/cognicia
ISSN 2658-8428

2020, VOL. 8, NO. 2, 262-276

Yuliana, I.A.I dan Valentina T.D. (2016). Dyadic coping dan kepuasan pernikahan suami istri dengan suami diabetes mellitus tipe II. Jurnal Psikologi Udayana,Vol.3,No.2, 324- 331. 